\title{
An overview of platelet products (PRP, PRGF, PRF, etc.) in the Iranian studies
}

\begin{abstract}
Aim: The aim of the study was to carry out a review of published studies on various platelet products in Iranian studies. Materials \& methods: Electronic databases were searched for relevant articles. Two review authors independently extracted data via a tested extraction sheet, and disagreements were resolved by a meeting with a third review author. Results: Bone disorders (25\%), wound and fistula (16\%), dental and gingival disorders (14\%) and osteoarthritis (11\%) have more relative frequency based on different fields. Conclusion: The necessity of pursuing standard protocols in the preparation of platelet products, stating the precise content of platelets and growth factors, and long-term follow-up of study subjects were the most important points in Iranian studies.
\end{abstract}

Lay abstract: Regenerative medicine includes special methods which can repair or replace new tissues beyond relief of symptoms in various diseases. Currently, platelet products (PRP, PRGF, etc.) can be considered as a tool for regenerative medicine. In this study we reviewed Iranian published studies in this field in the last 20 years. The primary object was to provide a clear vision of the quantity and quality of research while reviewing its methods and outcomes. This review highlights the potential application of platelet products, reported complications and their overall efficacy based on Iranian studies, and compares them with recent global findings in these fields.

First draft submitted: 20 February 2017; Accepted for publication: 16 June 2017; Published online: 28 July 2017

Keywords: blood platelets $\bullet$ platelet-rich fibrin $\bullet$ platelet-rich growth factor $\bullet$ platelet-rich plasma $\bullet \mathrm{PRF} \bullet \mathrm{PRGF} \bullet \mathrm{PRP} \bullet$ regenerative medicine

Regenerative medicine was defined by Mason and Dunnill as the replacement or renewal of the cell, tissues or organs with the aim of restoring their normal function [1]. This relatively new method is considered a primary therapeutic approach, particularly in some chronic illnesses lacking a definite treatment.

Regenerative medicine involves the use of stem cells, growth factor-rich platelets, biologic proteins, gene therapy and so on. Restoration of tissues and the absence of unwanted allograft reactions are among the benefits of this treatment. Platelets are among the cells that have potential in regenerative therapy. Abundance of growth factors and easy availability and processing have given them special attention. Other than growth factors and cytokines (including PDGF, TGF- $\beta$, IGF, VEGF) [2], these cells possess anti-inflammatory properties [3] and the cell itself and its products have recently been used in cellular scaffolds [4].

Platelets were first used to activate plasma products (thrombin and fibrinogen) by Cronkite et al. in 1944 during skin grafting [5]. Years after, in 1972, Matras et al. were
Seyed Ahmad Raeissadat ${ }^{1}$, Marzieh Babaee', Seyed Mansour Rayegani', Zahra Hashemi ${ }^{*, 1}$, Amir Ali Hamidieh$^{2}$, Parviz Mojgani ${ }^{3}$ \& Hossein Fouladi Vanda ${ }^{4}$ ${ }^{1}$ Clinical Research Development Center of Shahid Modarres Hospital \& Physical Medicine \& Rehabilitation Research Center of Shahid Beheshti University of Medical Sciences, Tehran, Iran ${ }^{2}$ Children's Medical Center, Tehran University of Medical Sciences, Tehran, Iran

${ }^{3}$ Rehabilitation and Medical Education Department, Iran Helal institute of Applied Sciences and Technology, affiliated to the Red Crescent Society of Iran, Tehran, Iran

${ }^{4}$ Rajaie Cardiovascular Medical and Research Center, Iran University of Medical Sciences, Tehran, Iran *Author for correspondence: Tel: +98 912754 2371; hashemi.zr@gmail.com 
the first who presented the idea of using fibrin glue for nerve repair [6,7]. Through the years, use of platelet products for various purposes in animal testing and clinical trials expanded. platelet-rich plasma (PRP) first was described by Marx et al. as suspension of platelet in plasma, with higher platelet than original blood collected $[8]$. Then, a second generation of platelet aggregation (platelet-rich fibrin [PRF]) was introduced which changed the quality of formulation according to speed and time of centrifugation [9,10]. Anticoagulant usage in PRP has been shown to decrease healing. Recently a new product, injectable PRF, was introduced without anticoagulant and different centrifuge speed and time in bone graft [11].

The common point between all studies is lack of definite protocol for preparation of products. Preparations of different platelet products are inconsistent both between and for the same clinician. The various parameters are: venesection (varying quantities and tubes), centrifugation of peripheral blood (varying force, speed and time) and aspiration of a platelet concentrate (varying needle gauge, aspiration technique and size of platelet-rich zone of plasma). It may or may not involve variation in the number of centrifuges (single or double spin), or the use of activation methods (addition of mechanical disturbance, UV light, thrombin or calcium chloride) [12].

In 2009, categorizing platelet products based on leukocyte and fibrinogen content was suggested with four groups [13]: pure PRP (P-PRP), leucocyte- and PRP (L-PRP), P-PR fibrin (P-PRF), and leucocyteand PR fibrin (L-PRF). Recently, Magalon et al. have introduced a new protocol for PRP classification, DEPA classification (dose of injected platelets, Efficacy of production, Purity of the PRP and Activation of PRP) [14].

Along with other countries, in the year 2000, research on the therapeutic applications of platelet derivatives in Iran began with the publication of the results of using autologous PDGFs in the treatment of diabetic ulcers [15]. During the following years, studies have diversified into various areas such as musculoskeletal, skin, wound healing and so on.

With the growing amount of regenerative medicine applications, especially regarding platelets and their derivatives in Iran, we elected to survey the existing published research by Iranian researchers on various platelet products in order to outline their quantitative and qualitative values. We also aimed to assess the current potential in terms of both facilities and personnel such as actively interested centers as well as existing eager individuals in this field. Whatever is gained from this study can be utilized in the improvement of policies for future research and treatment.

\section{Materials \& methods}

In this review, the literature search was performed by two people (one specialist and one resident of physical \& rehabilitation medicine). Disagreements were resolved by discussion; where resolution was not possible, a third review author was consulted. We included all published studies in Iran that evaluated the various platelet products, irrespective of publication status or language.

The same equivalent Persian words were also used in two valid Persian databases: Iranmedex and Irandoc and relevant articles up to 26 May 2016 were included. We imported the articles obtained from different databases into the bibliographic software package EndNoteX7 and merged them into one complete database.

\section{Search strategy}

In May 2016 we searched the following libraries and electronic databases for potentially relevant studies:

- PubMed

- MEDLINE

- Scopus

- Cochrane central

- Google scholar

- Iranmedex

- Irandoc

The terminologies that were used to identify these articles included:

- \# Platelet rich

- \# Plasma

- \# Growth factor

- \# Iran

Furthermore, we used a suitable combination of terminologies as mentioned above for searching.

After removing duplicates, two authors independently assessed the titles and abstracts of all retrieved papers for inclusion, using predefined inclusion and exclusion criteria.

\section{Inclusion criteria}

- Focus of study should be on any of these platelet products: P-PRP, L-PRP, P-PRF, L-PRF and PRGF;

- Study should be done by Iranian researchers and inside Iran; 
- Study design should be based on any of these study types: randomized clinical trials, nonrandomized clinical trials, case report, systematic review with or without meta-analysis, hypothesis.

\section{Exclusion criteria}

- If focus of study was on platelet disorders and platelet products used through intravascular injection;

- If the study was done by non-Iranian researchers or outside of Iran;

- If the publication type was a letter to editor or conference presentation.

\section{Data extraction}

For the included studies, two authors independently extracted data via a tested extraction sheet, and disagreements were resolved by a meeting with a third review author.

Information was categorized: that regarding platelet disorders and platelet products used through intravascular injection were removed and only articles of any type (except for letters to editor and conference presentation) were included if performed by Iranian researchers and inside the country.

\section{Results}

Among 2138 initial articles, 133 met the desired criteria (Figure 1).

In Iran, the publication of studies related to platelets and their derivatives commenced in the year 2000 and reached its peak in 2014, at which time 35 articles were published regarding this topic (Figure 2).

Figure 3 illustrates the relative frequency of studies performed in each of the different fields. The highest numbers belong to bone, wounds, dental and osteoarthritis.

From the different platelet products, PRP (72\%), PRGF (13.5\%) and PRF (12\%) were the most objectives studied.

Animal studies comprised the majority of research, the number of which was $55(41.3 \%)$ and two hypotheses had the lowest number of study types (Figure 4).

One hundred and twenty-five of the 133 studies have been performed in university centers, among which Mashhad university of medical sciences (15.8\%), Islamic Azad university (13.5\%) and Shahid Beheshti university of medical sciences $(12.8 \%)$ have the highest number of published papers.

We will now go into reviewing the studies in each area.

\section{Bone disorders}

The highest number of studies regarding platelet products in Iran has been performed in the field of bone disorders $(25 \%)$. The first of these were performed in 2005 [16] and 2006 [17] on cranial defects in animals. These studies (70\% of the total bone studies) cover areas such as repair of various bone defects (including cleft palate [18], site of a limb lengthening osteotomy [19], healing of fractures [20] particularly the non-healing types, osteonecrosis [21] and osteomyelitis [22]).

A variety of platelet derivatives (PRP, PRGF, PPP [23], PRF [24], platelet gel [25] and rh-PDGF [26]) were used in different techniques by Iranian researchers. Concurrent utilization of platelet products and autograft bone [27] or mesenchymal stem cells [24,26,28] in experimental studies as well as evaluation of the growth and differentiation of mesenchymal stem cells [23] for osteogenesis are among them.

Seventy-six percent of the experimental studies have reported good outcomes from the application of platelet products in their studies. All of those studies with no significant findings involved bone defect repair, mostly using PDGFs [26,29-31].

\section{Wounds \& fistulas}

Sixteen percent of the studies belong to this area. The first article published regarding platelet products was in the year 2000 by Aminian et al [15]. Regarding the use of PDGF on the treatment of diabetic foot ulcers.

The effects of platelet derivatives such as PRP, PRF [32,33] and PGRF [34] were studied on incisional $(57 \%)$ and diabetic (24\%) ulcers, anal fissure $(5 \%)$ and various fistules (14\%).

In $24 \%$ of these studies (one regarding anal fistulas and the others concerning incisional wounds), the effectiveness of these modalities was not significant [35-37].

\section{Dental \& gingival disorders}

2007 was the first year in Iran that PRP was used by Shamaei et al. to treat mandibular molar furcation [38]. After that in 2008, Aminabadi et al. suggested the use of PRP for the treatment of recurrent aphthous stomatitis [39]. Pulp capping [40], orthodontics [41], implants [42-44], filling bone defects [45-47], alveolar osteitis [48,49], and hard and soft palate repair [50-52] were afterward studied upon.

\section{Osteoarthritis}

This field includes $11 \%$ of all platelet product studies, $53 \%$ of which have been in the form of experimental human studies equally divided into RCTs and nonRCTs [53,54]. 


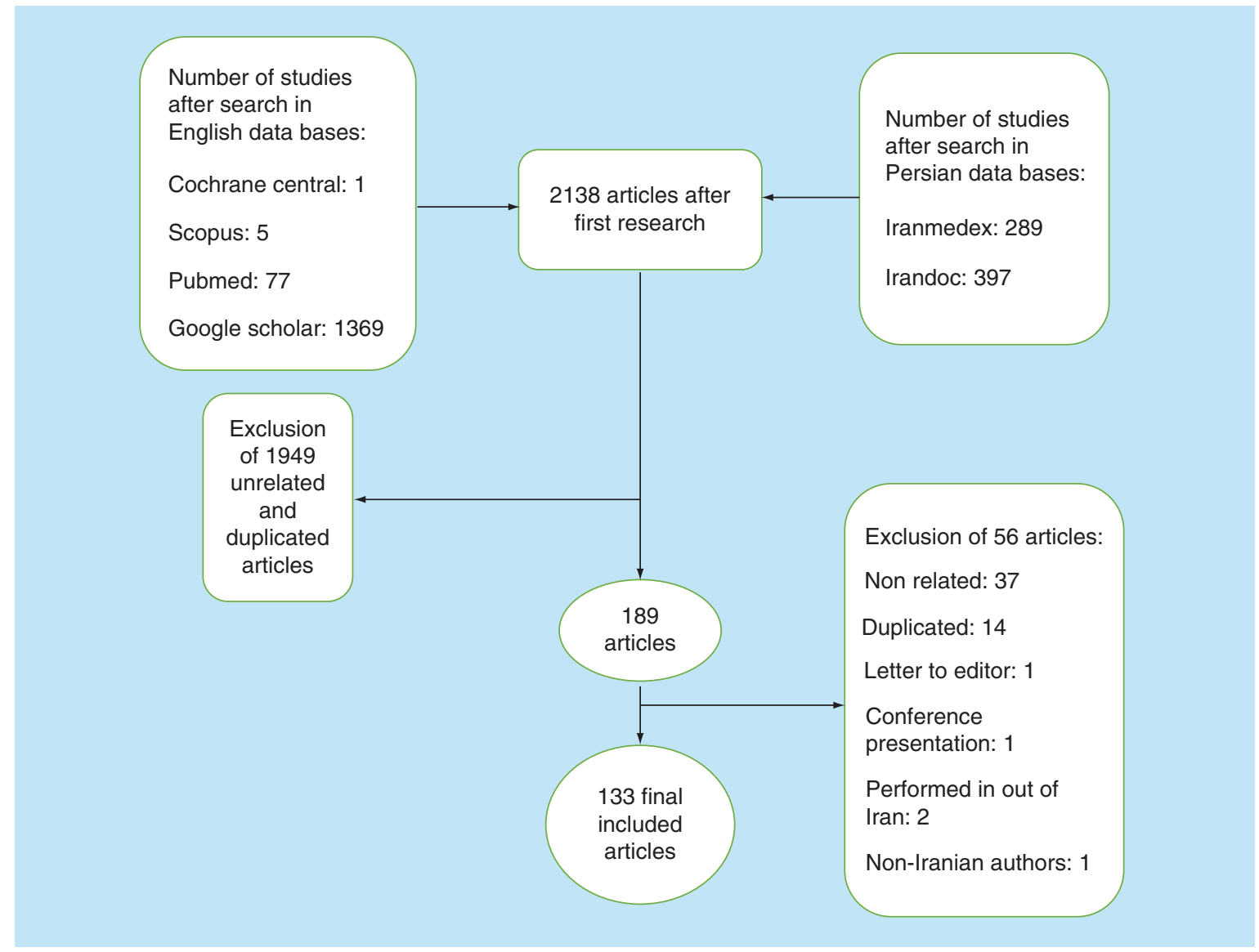

Figure 1. Stages of search and inclusion and exclusion of eligible articles.

The study by Kalbkhani et al. on animal models [55] and Raeissadat et al. on the human knee [56] in 2013 were the first published papers in this field.

PRP injection with or without sport education and its comparison with therapeutic exercise and paracetamol [57], with transcutaneous electrical nerve stimulation and exercise [58], three separate intra-articular injections of Hyalgan [59] and intra-articular steroid injection [60] in knee arthritis are all among the work of Iranian researchers. In all of these studies the effectiveness of PRP was shown to be more than the groups they were compared with. In all the animal studies in this field, platelet products were effective for up to 6 months of follow-up.

\section{Tendon \& ligament injuries}

In this field, the effect of platelet derivatives on rupture of anterior cruciate ligament (ACL) [61], lateral epicondylitis [62], plantar fasciitis [63] and frozen shoulder (adhesive capsulitis) [64] comprised the topics studied by Iranians. Among the 14 articles in this area, 9 were performed on animal subjects and 5 on humans (3 RCTs, 1 non-RCT and 1 case report). The first of the studies were performed and published in 2013 con- cerning the effect of PRP on healing of tendon damage in animal models [65] as well as ACL in humans.

\section{Skin \& aesthetic}

By stimulating the fibroblasts [66] and rejuvenation of the skin [67], application of PRP for skin care and aesthetic purposes has been one of the popular fields for Iranian researchers. This field is formed by $10 \%$ of all platelet-centered studies and covers treatment of conditions such as wrinkles [68], alopecia [69], grafts [70] and dark circles under the eyes [68]. Review articles and non-RCTs comprise the majority of these studies.

The study of Safari et al [71] could be one of the first on skin treatment, which involves assessment of the proliferation of keratinocytes in vitro in the presence of PDGF.

\section{Cartilage grafts}

There are a total of three studies in this area. Two of them are on animals and the third is a review article. The first of these was performed in 2012 by grafting a rabbit's auricular cartilage together with PRP application. The viability of the graft increased in this method [72]. 


\section{Peripheral nerve damage}

The two studies in this area were performed in 2015 [73] and 2016 [74], aiming to repair the sciatic nerve after cutting it in animal models. This has enjoyed better effects regarding the amount of myelin concentration.

\section{Ophthalmic tissue}

Corneal ulcers were the only subject studied in this area, in which two animal studies in 2012 [75] and 2013 [76] were conducted; PRP was found effective.

\section{Other areas}

Reduction in hepatotoxicity in animal studies after PRP injection [77], submucosal and periurethral injection of stem cells derived from autologous peripheral blood combined with PRP for treatment of urinary stress incontinence [78], as well as combination of PRP and fat injection in treating velopharyngeal insufficiency [79] cannot be included in the other categories. Therefore these, along with a variety of in vitro studies concerning diverse properties of platelet products, were put into a different category.

Other studies include proof of better results using PRP in fibrin scaffolds for proliferation and sustenance of mesenchymal stem cells compared with fetal bovine serum [80], increased differentiation of stem cells to megakaryocyte precursors in the presence of platelet growth factors [81], comparison of the mechanical properties of the membrane resulting from Early L-PRF compared with PRGF-Endoret system [82], proposal of a new method for platelet gel preparation using a special mixture of PRP, thrombin and calcium [83], and demonstrating that growth factors and platelet gel produced from expired platelets have the same concentration and function as those from fresh platelets [84].

\section{Complications of PRP}

Due to autologous injection, there is no immune reaction or allergy. Indeed, severe side effects are rare in the literature. The main risks are pain and infection. Use of a pain killer (non-NSAID) or local anesthesia decrease the pain. Another prevalent complication is heaviness in the site of injection [57,59].

\section{Discussion}

\section{Bone disorders}

Autogenous bone grafts are the gold standard for craniofacial and orbital bone defect repair [85]. Because of limitations in access as well as problems at the donor site (such as chronic pain and infection), tissue engineering using cell therapy (mesenchymal stem cells) [31], growth factors (PRP, PRGF) [86-88] and a combination of the both [89-92] has been suggested as bone graft alternatives in recent decades [26,93]. Iranian researchers have conducted human [94] and animal studies using different platelet products as well as their combination with various substances such as human amniotic fluid [95], hydroxyapatite [96,97], Persian Gulf coral [98] and deproteinized bovine bone mineral [99] for bone regeneration.

According to the review articles published in 2014 [93], 2015 [89] and 2016 [100], because of the differences in PRP preparation methods as well as the low number of controlled clinical studies, sufficient clinical evidence is lacking. Therefore, despite all of the merits associated with PRP, it should not yet be considered as a first-line therapy in this area. A review article on PRP applications in non-union of traumatic fractures in 2007 arrived to the same conclusion [101].

In 2007, Namazi pointed out the possibility of PRP use in osteomyelitis treatment, due to the presence of angiogenesis stimulating factors (such as VEGF) [22].

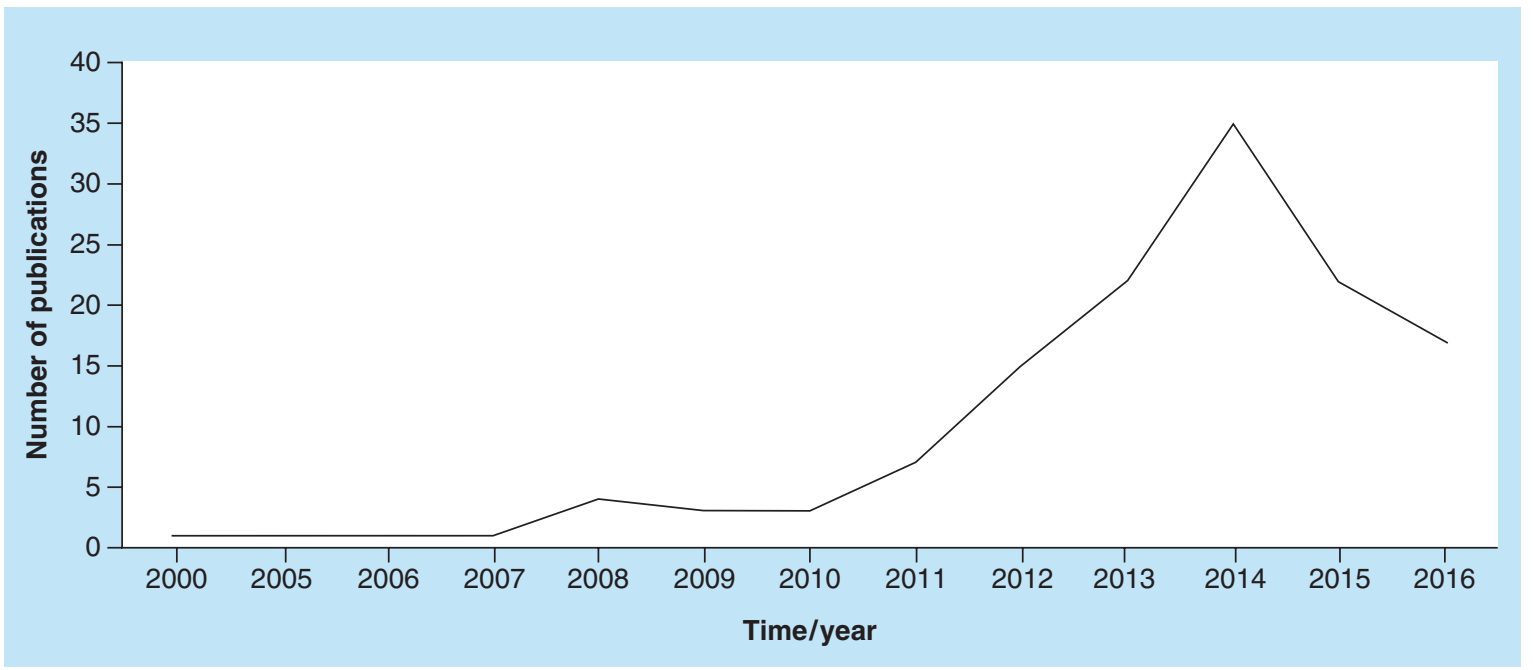

Figure 2. The number of articles published per year. 


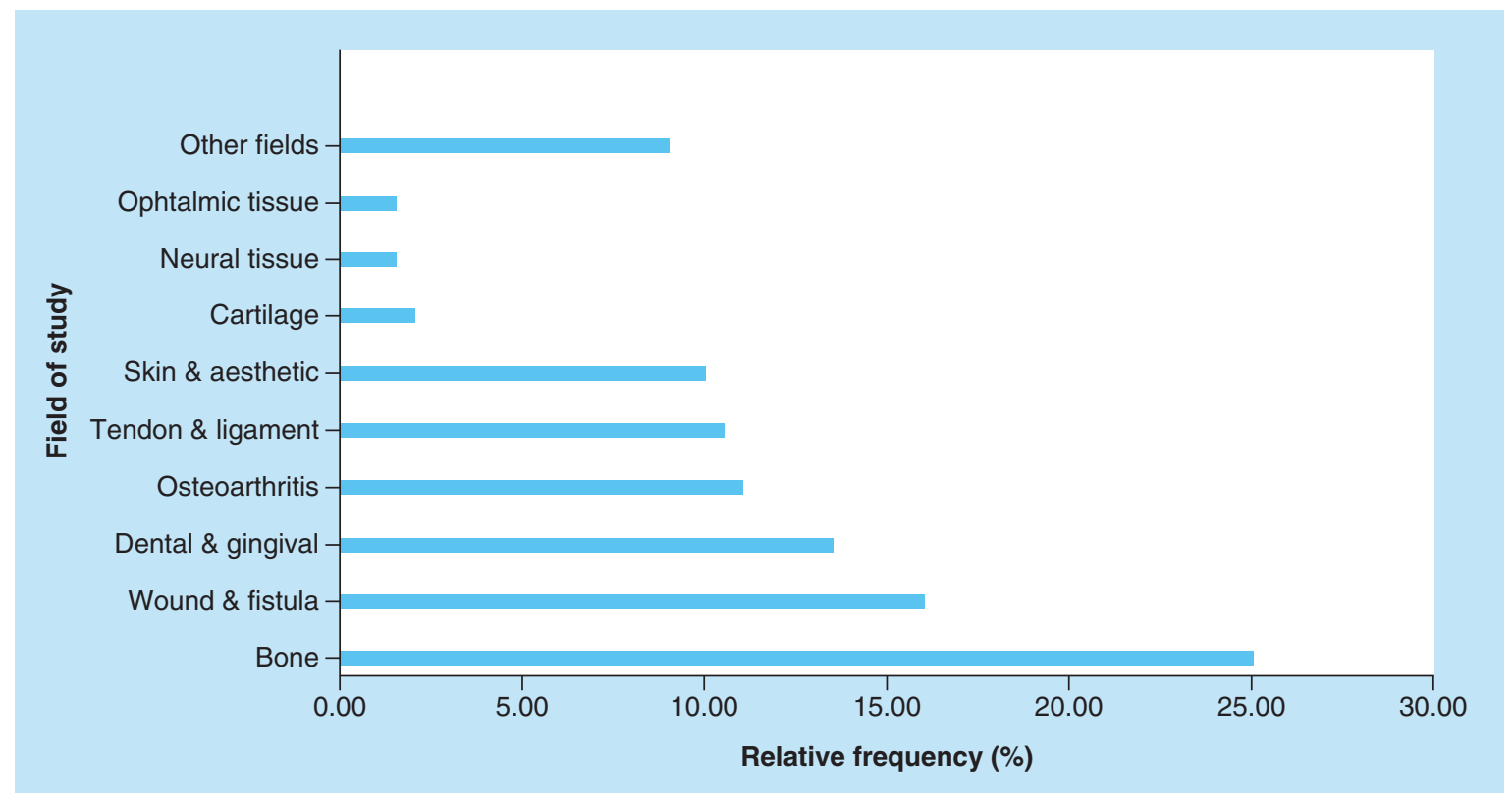

Figure 3. Relative frequency of studies performed in each field.

A number of human and animal studies showed its effectiveness in treatment of osteomyelitis of various bones [102-104].

\section{Wounds \& fistulas}

The majority of Iranian studies have performed RCTs on: incisional wounds [105-107], $42 \%$ of which have been performed on humans, including postcesarean section [108], pilonidal abscess extraction [109]. The nonRCTs include sternotomy [110] and soft tissue sarcoma excision [111] as a case report. The only study not demonstrating a meaningful effect on wound healing was the pilonidal sinus surgery. All studies conducted on diabetic foot ulcers [112-114] and fistulas [115-117] confirm the effect. An analysis of ten RCTs covering chronic ulcers, diabetic foot ulcers and venous ulcers was performed by Cochrane in 2016 [118]. Because of the small, low-quality RCTs in this study, the effectiveness of PRP on diabetic foot ulcers can only be considered as probable; and because of the low strength of the studies, the treatment effect was not possible to calculate.

Use of modern modalities such as PRP in conjunction with Chitosan Biodegradable Film in animal studies is also among the research related to wound healing performed in Iran [119].

\section{Dental \& gingival problems}

The effect of platelet derivatives on wound healing has led to the idea of their use in various dental and gum disorders. In the comparison between PRGF and PRF in vitro, PRGF showed a higher stimulatory role in the survival and proliferation of human gingival fibro- blasts [120] and was considered as a means of periodontal regeneration.

Platelet derivatives also have an important role in plastic surgery as preimplant connective tissue grafts, in healing of the graft donor site and prevention of adverse effects. In 2010, PRP was used in the donor site of animal models, although a meaningful effect was not seen regarding healing acceleration [121].

In addition, PRP effects have been studied on the proliferation and differentiation of pulp stem cells of humans [122].

\section{Osteoarthritis}

In a study, the prevalence of osteoarthritis in at least one joint in Iran was reported to be $20 \%, 19.34 \%$ of which affect the knee [123]. Therefore, knee osteoarthritis is among the most popular fields for Iranian researchers.

Animal studies commonly employ surgically induced osteoarthritis [124-126] followed by evaluating the effect of platelet products such as PRP, L-PRP [127] or PRF [128] in joints.

Based on a systematic review and meta-analysis conducted by Iranian researchers in 2016, the effectiveness of injection of hyaluronic acid and PRP in the knee joint was compared among 722 patients (from seven studies). Based on the WOMAC questionnaire, although both modalities were effective, PRP showed more promising outcomes [129]. The metaanalysis performed by Campbell et al. in 2015 [130] also pointed out the larger effect size, up to 1 year, of PRP injection compared with hyaluronic acid on the 
function of the knee. It seems that moderate-quality evidence supports the use of platelet in knee osteoarthritis [131].

In another study, PRP was compared with physiotherapy in treatment of chondromalacia [132]. A main drawback of this study was not restricting the use of NSAIDs until 1 week after intervention in both groups, since NSAIDs after treatment could significantly reduce the effects of PRP [131].

\section{Tendons \& ligaments}

Tendon injuries have always been a challenge for patient rehabilitation, in particular sports injuries. In most human and animal studies fitting within the scope of this article, PRP has been reported as effective [65,133]. Moderate-quality evidence shows the effectiveness of PRP injection in chronic lateral epicondylitis but its superior effect compared with autologous whole blood in treatment of this problem $[62,134]$ and plantar fasciitis [63] was not shown. Corticosteroid injection is another optional treatment for them [135].

The studies regarding Achilles tendon repair have all been performed on animals and PRP injection alone or in conjunction with laser therapy [136,137], hydrotherapy [138]. In some of these studies PRP injection has shown a meaningful effect [139-141], while in others the effect has not been significant [142].

\section{Skin \& aesthetic}

Because of the increase in the lifetime of adipose cells and stem cells together with higher differentiation, a mixture of PRP and autologous fat cells has been used as a deep filler for nasolabial, perioral and cheek wrinkles [143-145].

In a laboratory experimentation, AhmadiAshtiani et al. [146] discovered that the combination of PRP and an herbal extract has induced increased proliferation and lifetime of papillary derm cells, which could herald hopes for a treatment of hair loss. Bagherani's review article [69] also evaluated and approved PRP as a safe and effective treatment of alopecia areata although, in a review article, Jaffari [147] considered the level of evidence for the effectiveness of PRP in hair loss and hair grafting to be low to intermediate and the number of existing articles to be limited. According to her study, although current evidence confirms PRP's role in hair grafting, more research with higher level evidence is still required.

Other work used a type of laser in combination with simultaneous PRP injection for the treatment of acne, which not only did show a synergistic effect, but the results were worse [148].

In 2016, PRP and PRF were compared with a control group regarding the survival of a full skin graft in animals. After 4 weeks, PRP showed no meaningful difference with the controls and the results of PRF were actually worse than controls [70].

\section{Cartilage}

Since cartilage is an avascular tissue with little capacity for self-repair, tissue engineering via mesenchymal

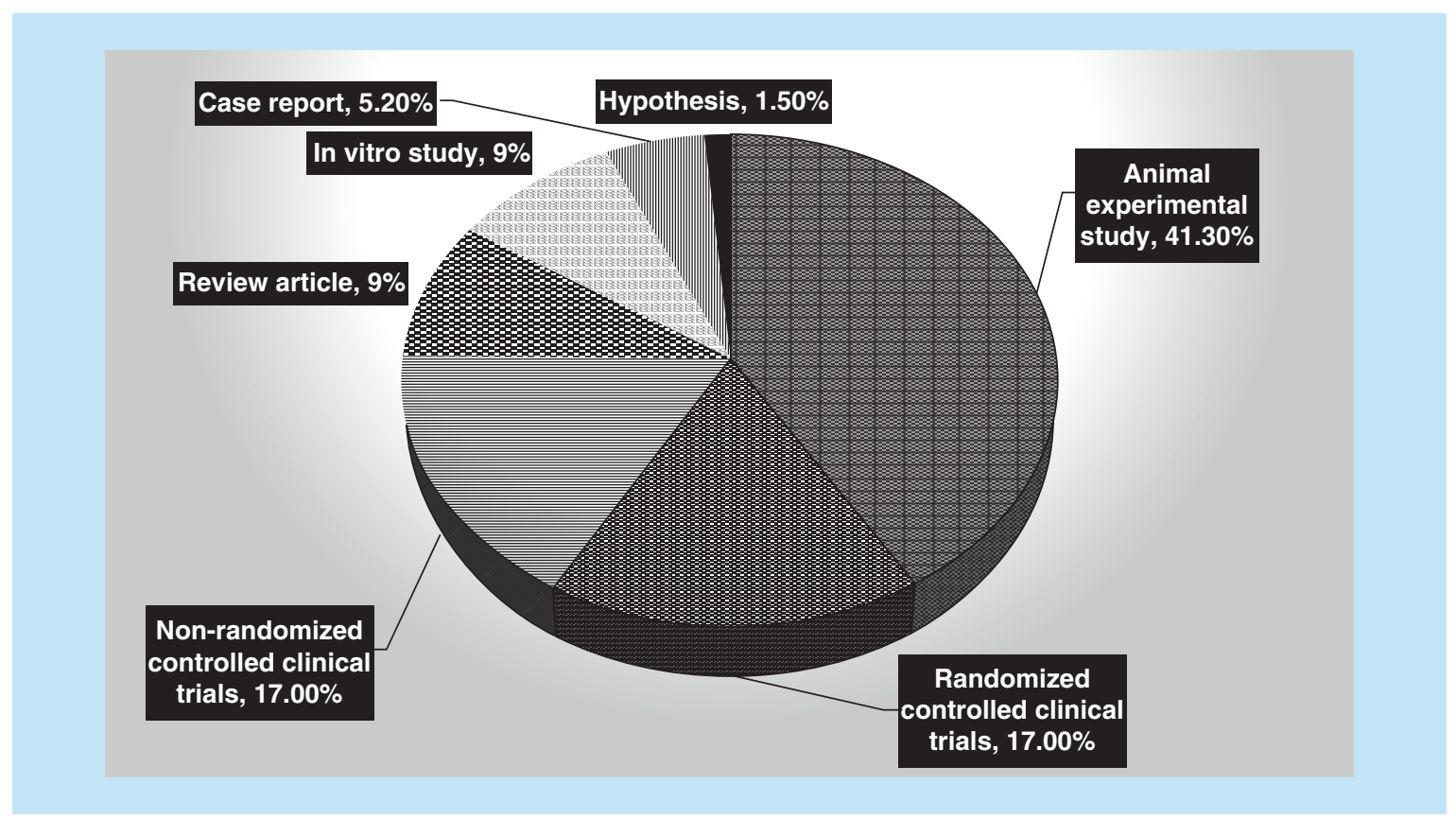

Figure 4. Relative frequency of each type of study conducted in Iran. 
Table 1. Relative frequency of each type of study in different fields.

\begin{tabular}{|c|c|c|c|c|c|c|}
\hline $\begin{array}{l}\text { Study type } \\
\text { research field }\end{array}$ & $\begin{array}{l}\text { Review } \\
\text { articles }\end{array}$ & $\begin{array}{l}\text { Randomized } \\
\text { clinical trials }\end{array}$ & $\begin{array}{l}\text { Non-randomized } \\
\text { clinical trials }\end{array}$ & Case reports & $\begin{array}{l}\text { Animal experimental } \\
\text { studies }\end{array}$ & $\begin{array}{l}\text { In vitro } \\
\text { studies }\end{array}$ \\
\hline Bone $^{\dagger}$ & $14.7 \%$ & $5.8 \%$ & $11.8 \%$ & - & $58.9 \%$ & $5.8 \%$ \\
\hline Dental \& gingival & - & $37.5 \%$ & $18.7 \%$ & $6.3 \%$ & $25 \%$ & $12.5 \%$ \\
\hline Osteoarthritis & - & $26.7 \%$ & $26.7 \%$ & $7.1 \%$ & $39.5 \%$ & - \\
\hline Skin \& aesthetic & $28.6 \%$ & $14.3 \%$ & $28.6 \%$ & - & $21.4 \%$ & $7.1 \%$ \\
\hline Cartilage & $33.3 \%$ & - & - & - & $33.3 \%$ & $33.3 \%$ \\
\hline Neural tissue & - & - & - & - & $100 \%$ & - \\
\hline Ophthalmic tissue & - & - & - & - & $100 \%$ & - \\
\hline Others field ${ }^{\dagger}$ & $9 \%$ & - & $9 \%$ & $9 \%$ & $9 \%$ & $55 \%$ \\
\hline
\end{tabular}

stem cells, cellular scaffolds and chondrogenic growth factors are of great significance.

In their review article, Kabiri and colleagues [149] confirmed the positive influence of PRP in chondrogenesis. They believe the various methods of PRP preparation in different studies as well as failure to mention the concentration of growth factors in the products to be among reasons for the contradictory results seen in some studies.

\section{Peripheral nerves}

In 2015, a silicon tube filled with PRP [73], and in 2016 PRP injection under the perineurium proximal and distal to a cut in the sciatic nerve [74] were compared with a control group (only normal saline) in animals. There was no significant difference in the number of axons.

By taking a glance at the studies performed, the diversity of platelet products as well as their various uses can be observed. The range of studies of Iranian scientists shows the high potential presence of different products with various goals available to the patients. To the same extent, the heterogeneous nature of the study results makes judgement and clinical decisionmaking a challenge in this field.

According to studies, the growth factor concentration, platelet count, presence of other cells such as leukocytes as well as the mechanism of platelet content release all vary based on the method which the PRP has been prepared [150,151]. Therefore, following standard protocols and mentioning the aforementioned properties of the prepared products seems necessary, which is lacking in some studies. Creating and committing to standard principles in preparation of platelet derivatives is one of the requirements of their presence in clinical practice.

Based on a review article by Moshiri, although more than $90 \%$ of the in vivo and in vitro studies acknowl- edge the effectiveness of PRP in tissue regeneration, more than $50 \%$ of human studies have not reached positive findings. Researchers believe that in most animal studies, allogenic PRP is used, while in human studies the PRP is mainly autologous. They have come up with the hypothesis that because of the inflammatory process caused by allogenic PRP injection, acceleration of the tissue regeneration process is more possible [152].

While it has been mentioned that PRP can affect the growth of tumors [153], there is no study showing PRP to be cancerogenic due to the presence of growth factors. Long-term safety of these products should also be established through follow-up.

Between the 133 studies, in 1 RCT studying wound healing after pilonidal sinus removal, there was a higher rate of infection in the PRP group compared with the control group [109], which has not been reported in other similar studies. This makes description of the exact method of preparation and injection as well as a comparison between presence of coexisting diseases in control and intervention groups imperative prior to any conclusions regarding side effects of PRP injection.

Another important consideration is proper outcome assessment. Some studies with similar methodologies have sometimes had opposite conclusions. The inclusion of explanations regarding the reasoning behind the conclusion can help the readers and affect the final conclusion. Age group of those studied as well as the duration of follow-up of effects should also be included in study evaluation [154].

\section{Rules of PRP use in Iran}

During the past few years, and along with the results of scientific literature, the ministry of health and medical education has gradually changed their stance regarding PRP. In 2011, clinical workshops and provision of con- 
tinuous medical education certificates were banned. Two years later, manufacture and sale of the first PRP preparation kit was approved for orthopedic uses only, and trained physicians allowed to use the kits for musculoskeletal disorders.

In 2015, the Iranian Food and Drug Organization approved the use of PRP in treatment of chronic ulcers, regeneration of musculoskeletal soft tissue, and pain reduction in knee osteoarthritis (when steroids and hyaluronic acid have shown to have no effect, and as pain relief until joint replacement). It has also been stated that due to evidence on skin rejuvenation not being sufficient, PRP use in cosmetic procedures has not yet been approved by this association.

To compare this with other countries, the USA presented a paper about 'US Definitions, Current Use and FDA Stance on Use of Platelet-Rich Plasma in Sports Medicine'. In this article, PRP falls under the purview of the US FDA's Center for Biologics Evaluation and Research. According to the code of regulation (FDA's 21 CFR 1271), it is not necessary for blood product to follow the FDA's traditional regulatory pathway that includes animal studies and clinical trial. For bringing PRP preparation systems to the market, the $510(\mathrm{k})$ application is recommended. Today most of these products are related to use and a mix of PRP for bone graft [155]. Two other studies investigated the effect of PRP in musculoskeletal disorders in Korea and Australia $[12,156]$. The Australian paper studied the pattern of PRP among sport physicians and the Korean paper discussed PRP therapy in knee joint problem and legal perspective in Korea.

As far as we know, there is no similar literature in other countries which survey all fields related to platelet products. However, there is an increasing trend in application of platelet products in other countries especially in developing countries such as Turkey, Egypt, Saudi Arabia and so on. According to our research in the Medline/PubMed database regarding PRP applica- tion in the aforementioned countries, Turkish researchers and researchers of Saudi Arabia have the most and least publications in this area, respectively. In Turkish studies, just like Iranian research, effects on bone and joints comprised the majority of the work. In Turkey, dental and tendon fields had the second highest amount of research, but in our studies wound healing is the second most common. Based on our knowledge, Turkish researchers do not have any publications on ophthalmic disorders but they have performed several studies concerning the ENT field and PRP protocols. Egyptians had fewer publications than Iranians in the application of PRP in bone and joint disorders, and skin and aesthetics have been the most popular fields for them. Generally, these differences in numbers of published studies do not necessarily reflect the interest of application of platelet product in their countries and may have been affected by more common health problems and accessibility to the platelet products as well as the governmental rules for use of these products.

\section{Conclusion \& future perspective}

Despite the lack of statistics about scope of studies in other countries regarding use of platelet derivatives, it seems that Iranian researches follow this topic seriously, particularly in academic centers. Gradually the quality of research is improving, and the fields of platelet-product-studies are expanding which could lay the foundation of further, and at the same time more logical, clinical applications.

The necessity of pursuing standard protocols in preparation of the platelet products, stating the precise content of platelets and growth factors and long-term follow-up of study subjects were the most important factors for Iranian studies.

\section{Financial \& competing interests disclosure}

The authors have no relevant affiliations or financial involvement with any organization or entity with a financial interest in or financial conflict with the subject matter or mate-

\section{Executive summary}

- There is growing trend toward regenerative medicine for management of chronic and disabling diseases.

- Platelet cells play a key role in recent research owing to effects of their various growth factors and cytokines with healing properties.

- PRP with $72 \%$, then PRGF (13.5\%) and PRF (12\%) were the most attractive platelet products in Iranian research.

- $41.3 \%$ of studies utilized an animal experimental method, while randomized clinical trials (17\%) and nonrandomized clinical trials (17\%) were the next in rank.

- Bone disorders (25\%), wound and fistula (16\%), dental and gingival disorders (14\%) and osteoarthritis (11\%) have more relative frequency based on different fields.

- The necessity of pursuing standard protocols in the preparation of the platelet products, stating the precise content of platelets and growth factors and long-term follow-up of study subjects were the most important factors in Iranian studies. 
rials discussed in the manuscript. This includes employment, consultancies, honoraria, stock ownership or options, expert testimony, grants or patents received or pending, or royalties.

No writing assistance was utilized in the production of this manuscript.

\section{Open access}

This work is licensed under the Creative Commons Attribution 4.0 License. To view a copy of this license, visit http://creativecommons.org/licenses/by/4.0/

\section{References}

Papers of special note have been highlighted as: $\bullet$ of interest; $\bullet \bullet$ of considerable interest

1 Mason C, Dunnill P. A brief definition of regenerative medicine. Regen. Med. 3(1), 1-5 (2007).

2 Anitua E, Sánchez M, Orive G, Andía I. The potential impact of the preparation rich in growth factors (PRGF) in different medical fields. Biomaterials 28(31), 4551-4560 (2007).

3 El-Sharkawy H, Kantarci A, Deady J et al. Platelet-rich plasma: growth factors and pro-and anti-inflammatory properties. J. Periodontol. 78(4), 661-669 (2007).

4 Murray MM, Spindler KP, Devin C et al. Use of a collagenplatelet rich plasma scaffold to stimulate healing of a central defect in the canine ACL. J. Orth. Res. 24(4), 820-830 (2006).

5 Abel ME, Chiu YS, Russell TR, Volpe PA. Autologous fibrin glue in the treatment of rectovaginal and complex fistulas. Dis. Colon Rectum 36(5), 447-449 (1993).

6 Matras H, Dinges H, Lassmann H, Mamoli B. Zur nahtlosen interfaszikulären Nerventransplantation im Tierexperiment. Wien. Med. Wochenschr. 122(37), 517-523 (1972).

7 Matras H, Dinges H, Mamoli B, Lassmann H. Non-sutured nerve transplantation: a report on animal experiments. J. Maxillofac. Surg. 1 37-40 (1973).

8 Marx RE, Carlson ER, Eichstaedt RM, Schimmele SR, Strauss JE, Georgeff KR. Platelet-rich plasma: growth factor enhancement for bone grafts. Oral Surg. Oral Med. Oral Pathol. Oral Radiol. Endod. 85(6), 638-646 (1998).

9 Dohan DM, Choukroun J, Diss A et al. Platelet-rich fibrin (PRF): a second-generation platelet concentrate. Part I: technological concepts and evolution. Oral Surg. Oral Med. Oral Pathol. Oral Radiol. Endod. 101(3), e37-e44 (2006).

10 Choukroun J, Diss A, Simonpieri A et al. Platelet-rich fibrin (PRF): a second-generation platelet concentrate. Part $\mathrm{V}$ : histologic evaluations of PRF effects on bone allograft maturation in sinus lift. Oral Surg. Oral Med. Oral Pathol. Oral Radiol. Endod. 101(3), 299-303 (2006).

11 Wang X, Zhang Y, Choukroun J, Ghanaati S, Miron RJ. Effects of an injectable platelet-rich fibrin on osteoblast behavior and bone tissue formation in comparison to plateletrich plasma. Platelets doi:10.1080/09537104.2017.1293807 (2017) (Epub ahead of print).

\section{Author contributions}

SA Raeissadat was the first designer of this study and then revised and translated the article into English. He also participated as a third review author for consultant (inclusion and exclusion of articles). M Babaee gathered data and participated in writing the article. SM Rayegani revised the final article. Z Hashemi gathered data and analysed them and participated in writing the article and is corresponding author. AA Hamidieh revised the final article. H Fouladi $V$ and $P$ Mojgani participated in submission and editing the final article.

12 Samra DJ, Orchard JW. Patterns of platelet-rich plasma use among Australasian sports physicians. BMJ Open Sport Exerc. Med. 1(1), e000054 (2015).

- Above-mentioned references were the only articles working on the state of PRP research and application specially in their country.

13 Dohan Ehrenfest DM, Rasmusson L, Albrektsson T. Classification of platelet concentrates: from pure plateletrich plasma (P-PRP) to leucocyte- and platelet-rich fibrin (L-PRF). Trends Biotechnol. 27(3), 158-167 (2009).

14 Magalon J, Chateau AL, Bertrand B et al. DEPA classification: a proposal for standardising PRP use and a retrospective application of available devices. BMJ Open Sport Exerc. Med. 2(1), e000060 (2016).

15 Aminian B, Shams M, Omrani GR, Soveyd M. Topical autologous platelet-derived growth factors in the treatment of chronic diabetic ulcers. Arch. Iran. Med. (2000). www.ams.ac.ir/AIM/0032/aminian0032.html

16 Soleymani SY, Khoursand A, Motahari P, Dehghan M, Shafiee AM. Evaluation of platelet-rich plasma in combination with deproteinized bovine bone mineral in the rabbit cranium: a pilot study. J. Dent. (Tehran, Iran) 2(4), 127-134 (2005).

17 Shayesteh YS, Shafiee M, Khorsand A, Dehghan M. Evaluation of platelet-rich plasma in combination with deproteinized bovine bone mineral in the rabbit cranium. Perio 4(3), 1-9 (2006).

18 Khajehahmadi S. Maxillary alveolar bone grafting: the role of platelet-rich plasma (PRF). Int. J. Pediatr. 2(2.3), 32 (2014).

19 Dehghan MM, Baghaban Eslaminejad M, Motallebizadeh $\mathrm{N}$ et al. Transplantation of autologous bone marrow mesenchymal stem cells with platelet-rich plasma accelerate distraction osteogenesis in a canine model. Cell J. 17(2), 243-252 (2015).

20 Namazi H, Mehbudi A. Investigating the effect of intraarticular PRP injection on pain and function improvement in patients with distal radius fracture. Orthop. Traumatol. Surg. Res. 102(1), 47-52 (2016).

21 Sarkarat F, Motamedi MHK, Jahanbani J, Sepehri D, Kahali R, Nematollahi Z. Platelet-rich plasma in treatment of zoledronic acid-induced bisphosphonate-related osteonecrosis of the jaws. Trauma Mon. 19(2), e17196 (2014). 
H. Platelet-rich plasma as a novel therapeutic agent in osteomyelitis. Med. Hypotheses 69(3), 706 (2007). Comparative effect of human platelet derivatives on proliferation and osteogenic differentiation of menstrual blood-derived stem cells. Mol. Biotechnol. 56(3), 223-231 (2014).

24 Behnia H, Khojasteh A, Soleimani M, Tehranchi A, Atashi A. Repair of alveolar cleft defect with mesenchymal stem cells and platelet derived growth factors: a preliminary report. J. Craniomaxillofac. Surg. 40(1), 2-7 (2012).

25 Amani M, Amirizadeh N, Soleymani M, Malekan H, Habibi RM, Bashtar M. Effect of growth factors of platelet gel on proliferation and differentiation of mesenchymal stem cells. Iran Biomed. J. 6(2), 71-83 (2009).

26 Khojasteh A, Dashti SG, Dehghan MM, Behnia H, Abbasnia P, Morad G. The osteoregenerative effects of platelet-derived growth factor BB cotransplanted with mesenchymal stem cells, loaded on freeze-dried mineral bone block: a pilot study in dog mandible. J. Biomed. Mater. Res. B Appl. Biomater. 102(8), 1771-1778 (2014).

27 Lafzi A, Shirmohammadi A, Faramarzi M, Jabali S, Shayan A. Clinical comparison of autogenous bone graft with and without plasma rich in growth factors in the treatment of grade II furcation involvement of mandibular molars. J. Dent. Res. Dent. Clin. Dent. Prospects 7(1), 22 (2013).

28 Behnia H, Khojasteh A, Kiani MT et al. Bone regeneration with a combination of nanocrystalline hydroxyapatite silica gel, platelet-rich growth factor, and mesenchymal stem cells: a histologic study in rabbit calvaria. Oral Surg. Oral Med. Oral Pathol. Oral Radiol. 115(2), e7-e15 (2013).

29 Moghaddas H, Kadkhodazadeh M, Pezeshkfar A. Comparison of the palatal connective tissue graft as a membrane with collagen membrane in combination with Bio-Oss and PRGF for treatment of intrabony defects: a randomized clinical trial. J. Dental School 1 30-40 (2012).

30 Mogharehabed A, Birang R, Torabinia N, Nasiri S, Behfarnia P. Socket preservation using demineralized freezed dried bone allograft with and without plasma rich in growth factor: a canine study. Dent. Res. J. (Isfahan) 11(4), 460 (2014).

31 Khojasteh A, Eslaminejad MB, Nazarian H. Mesenchymal stem cells enhance bone regeneration in rat calvarial critical size defects more than platelete-rich plasma. Oral Surg. Oral Med. Oral Pathol. Oral Radiol. Endod. 106(3), 356-362 (2008).

32 Alishahi MK, Mofidpoor H, Goli AA, Alishahi MaK. Histopathological evaluation of the effect of platelet-rich fibrin on canine cutaneous incisional wound healing. Iranian J. Vet. Sci. Technol. 5(2), 19-32 (2013).

33 Asadi M, Alamdari DH, Rahimi HR et al. Treatment of lifethreatening wounds with a combination of allogenic plateletrich plasma, fibrin glue and collagen matrix, and a literature review. Exp. Ther. Med. 8(2), 423-429 (2014).

34 Moradi O, Ghamsari SM, Mahdi Dehghan M, Sedaghat R, Akbarein H. Effects of platelet rich plasma (PRP) and platelet rich growth factor $\left(\mathrm{PRGF}^{\circledR}\right)$ on the wound healing of distal part of limbs in horses. Iran. J. Vet. Surg. 8(1), 41-48 (2013).
35 Jamshidzadeh A, Mardani Z, Ghahramani L et al. Topical platelet lysate hydrogel in patients with anal fissure. Ann. Colorectal Res. 2(3), e24266 (2014).

36 Kazemi MH, Sardari K, Emami M, Movassaghi AR, Afkhami GA, Malekzadeh S. Efficacy of autologous plateletrich plasma (PRP) activated by thromboplastin-D on the repair and regeneration of wounds in dogs. Iran. J. Vet. Surg. 3(4), 9 (2008).

37 Malekzadeh S, Sardari K, Emami M, Kazemi Mehrjerdi H, Movassaghi AR, Afkhami GA. Effects of platelet-rich plasma (PRP) on cutaneous regeneration and wound healing in dogs treatedwith dexamethasone. Comp. Clin. Path. 20(2), 155-162 (2011).

Shamaei M, Taleghany F, Kiany A. Clinical evaluation of Bio-Oss alone and in combination with PRP in the treatment of grade II mandibular molar furcation defects. J. Islam. Dent. Assoc. Iran 19(1), 7-12 (2007).

Aminabadi NA. Plasma rich in growth factors as a potential therapeutic candidate for treatment of recurrent aphthous stomatitis. Med. Hypotheses 70(3), 529-531 (2008).

40 Moradi S, Saghravanian N, Moushekhian S, Fatemi S, Forghani M. Immunohistochemical evaluation of fibronectin and tenascin following direct pulp capping with mineral trioxide aggregate, platelet-rich plasma and propolis in dogs' teeth. Iran Endod. J. 10(3), 188 (2015).

41 Bayani S, Masoomi F, Aghaabbasi S, Farsinejad A. Evaluation of the effect of platelet-released growth factor and immediate orthodontic loading on the removal torque of miniscrews. Int. J. Oral Maxillofac. Implants 31(2), 471-477 (2016).

42 Birang R, Torabi A, Shahabooei M, Rismanchian M. Effect of plasma-rich in platelet-derived growth factors on periimplant bone healing: an experimental study in canines. Dent. Res. J. (Isfahan) 9(1), 93 (2012).

43 Fahami N, Amini S. Effect of platelet rich plasma on implant stability in mandible. J. Periodontol. Implant Dentistry 7(2), 50-54 (2016)

44 Birang R, Tavakoli M, Shahabouei M, Torabi A, Dargahi A, Soolari A. Investigation of peri-implant bone healing using autologous plasma rich in growth factors in the canine mandible after 12 weeks: a pilot study. Open Dent. J. 5, 168 (2011).

45 Esfahanian V, Moghaddas H, Moghaddas O. Efficacy of connective tissue as a membrane with an organic bone using platelet-rich plasma in the treatment of intrabony vertical defects. J. Isfahan Dental School 8(1), 1-17 (2012). Treatment of mandibular molar class II furcation defects in humans with bovine porous bone mineral in combination with plasma rich in growth factors. J. Dent. (Tehran, Iran) 9(1), 41 (2012).

47 Rahpeyma A. Platelet-rich plasma as filling material in open sinus lift surgery. Int. J. Pediatr. 2(2.3), 45-45 (2014).

48 Haraji A, Lassemi E, Motamedi MH, Alavi M, Adibnejad S. Effect of plasma rich in growth factors on alveolar osteitis. Natl J. Maxillofac. Surg. 3(1), 38-41 (2012).

49 Eshghpour M, Dastmalchi P, Nekooei AH, Nejat A. Effect of platelet-rich fibrin on frequency of alveolar osteitis 
following mandibular third molar surgery: a double-blinded randomized clinical trial. J. Oral Maxillofac. Surg. 72(8), 1463-1467 (2014).

50 Lafzi A, Chitsazi M, Farahani R, Faramarzi M. Comparative clinical study of coronally advanced flap with and without use of plasma rich in growth factors in the treatment of gingival recession. Am. J. Dent. 24(3), 143-147 (2011).

51 Lafzi A, Faramarzi M, Shirmohammadi A, Behrozian A, Kashefimehr A, Khashabi E. Subepithelial connective tissue graft with and without the use of plasma rich in growth factors for treating root exposure. J. Periodont. Implant Sci. 42(6), 196-203 (2012).

52 Shaban B, Eshghpour M. Efficacy of platelet-rich plasma in treatment of periodontal defects following surgical extraction of mandibular third molar. J. Pharm. Biol. Sci. 10(2), 79-82 (2015).

53 Bagherifard A, Jabalameli M, Jahansouz A et al. Platelet-rich plasma injection for symptomatic knee osteoarthritis. Shafa Orthopedic J. 2(3), 162-172 (2015).

54 Jivan SJ, Shariati-Sarabi Z, Afshari JT et al. Effectiveness of intra-articular injection of platelet-rich plasma on clinical improvement of patients with knee osteoarthritis. Ann. Rheum. Dis. 74(Suppl. 2), 1194-1194 (2015).

55 Kalbkhani M, Dehghani S, Najafpour A, Ghorbanzadeh N. The effect of autogenous platelet rich plasma on experimentally induced osteoarthritis in rabbit's stifles joint: a radiological assessment. J. Animal Poultry Sci. 2(1), 27-38 (2013).

56 Raeissadat SA, Rayegani SM, Babaee M, Ghorbani E. The effect of platelet-rich plasma on pain, function, and quality of life of patients with knee osteoarthritis. Pain Res. Treat. 2013, 165967 (2013)

57 Rayegani SM, Raeissadat SA, Taheri MS et al. Does intra articular platelet rich plasma injection improve function, pain and quality of life in patients with osteoarthritis of the knee? A randomized clinical trial. Orthop. Rev. (Pavia) 6(3), 5405 (2014).

58 Angoorani H, Mazaherinezhad A, Marjomaki O, Younespour S. Treatment of knee osteoarthritis with plateletrich plasma in comparison with transcutaneous electrical nerve stimulation plus exercise: a randomized clinical trial. Med. J. Islam. Repub. Iran 29, 223-220 (2015).

59 Raeissadat SA, Rayegani SM, Hassanabadi $\mathrm{H}$ et al. Knee osteoarthritis injection choices: platelet- rich plasma (PRP) versus hyaluronic acid (a one-year randomized clinical trial). Clin. Med. Insights Arthritis Musculoskelet. Disord. 8, 1-8 (2015).

60 Forogh B, Mianehsaz E, Shoaee S, Ahadi T, Raissi GR, Sajadi S. Effect of single injection of platelet-rich plasma in comparison with corticosteroid on knee osteoarthritis: a double-blind randomized clinical trial. J. Sports Med. Phys. Fitness 56(7-8), 901-908 (2015).

61 Mirzatolooei F, Alamdari MT, Khalkhali HR. The impact of platelet-rich plasma on the prevention of tunnel widening in anterior cruciate ligament reconstruction using quadrupled autologous hamstring tendon: a randomised clinical trial. Bone Joint J. 95-B(1), 65-69 (2013).

62 Raeissadat SA, Sedighipour L, Rayegani SM, Bahrami $\mathrm{MH}$, Bayat M, Rahimi R. Effect of platelet-rich plasma
(PRP) versus autologous whole blood on pain and function improvement in tennis elbow: a randomized clinical trial. Pain Res. Treat. 2014, 191525 (2014).

63 Vahdatpour B, Kianimehr L, Ahrar MH. Autologous platelet-rich plasma compared with whole blood for the treatment of chronic plantar fasciitis; a comparative clinical trial. Adv. Biomed. Res. 5, 84 (2016).

64 Aslani H, Nourbakhsh ST, Zafarani Z et al. Platelet-rich plasma for frozen shoulder: a case report. Arch. Bone Joint Surg. 4(1), 90-93 (2016).

65 Dehghani NF, Tabatabaei NA, Dehghani S. Evaluation of the effect of platelet rich plasma (PRP) in tendon gap healing by measuring collagen synthesis in guinea pig. Iran. J. Vet. Surg. 8(1), 23-28 (2013).

66 Adibmoradi M, Moradi HR, Kalantari HA, Adibmoradi G. Study of histomorphometric changes in adult rats skin following injection of PRP and PPP. J. Vet. Res. 71(1), 1-8 (2016).

67 Banihashemi M, Nakhaeizadeh S. An introduction to application of platelet rich plasma (PRP) in skin rejuvenation. Rev. Clin. Med. 1(2), 38-43 (2014).

68 Mehryan P, Zartab H, Rajabi A, Pazhoohi N, Firooz A. Assessment of efficacy of platelet-rich plasma (PRP) on infraorbital dark circles and crow's feet wrinkles. J. Cosmet. Dermatol. 13(1), 72-78 (2014).

69 Bagherani N. Is platelet-rich plasma effective in the treatment of alopecia areata? Dermatol. Ther. 48(1), 57-59 (2015).

70 Latifi N, Rezvani N, Fatemi MJ, Nourian M, Araghi S, Bagheri T. Examining the effects of platelet-rich plasma and platelet-rich fibrin on autologous full thickness skin graft survival in rats. Tehran Univ. Med. J. 73(11), 767-777 (2016).

71 Safari M, Ghorbani R, Emami M, Yousefi B, Ghahari L. The effects of GH and PDGF on the growth and proliferation of the epithelial cells. Koomesh 9(3), 229-235 (2008). http://en.journals.sid.ir/ViewPaper.aspx?ID =121107

72 Manafi A. Effects of platelet-rich plasma on cartilage grafts in rabbits as an animal model. World J. Plast. Surg. 1(2), 91 (2012).

73 Abbasipour-Dalivand S, Mohammadi R, Mohammadi V. Effects of local administration of platelet rich plasma on functional recovery after bridging sciatic nerve defect using silicone rubber chamber: an experimental study. Bull. Emerg. Trauma 3(1 JAN), 1-7 (2015).

74 Fatemi MJ, Pakfetrat F, Akhoondinasab MRA et al. The effect of sub-epineural platelet-rich plasma (PRP) on regeneration of the sciatic nerve in a rat model. Tehran Univ. Med. J. 73(10), 693-699 (2016).

75 Elahi K, Gh M. Effects of topical heterologous blood serum and bovine thrombin activated platelet rich plasma on experimental corneal stromal ulcers in rabbit. Adv. Environ. Biol. (6), 95-99 (2012).

76 Khaksar E, Aldavood S, Abedi G, Sedaghat R, Nekoui $\mathrm{O}$, Zamani-Ahmadmahmudi $\mathrm{M}$. The effect of subconjunctival platelet-rich plasma in combination with topical acetylcysteine on corneal alkali burn ulcer in rabbits. Comp. Clin. Path. 22(1), 107-112 (2013). 

Effect of platelet-rich plasma on CCl4-induced chronic liver injury in male rats. Int. J. Hepatol. 2014, 932930 (2014).

78 Keshvari M. The effect of autologus peripheral blood cells transplantation along with platelet rich plasma in the treatment of patients with stress incontinence. Int. J. Pediatr. 2(2.3), 78 (2014).

79 Fathi HR, Fereyduni F. Treatment results of combined platelet-rich plasma and fat injection in patients with velopharyngeal insufficiency. Tehran Univ. Med. Sci. 71(7), (2013).

80 Sadeghian M, Hashemibeni B, Mardani M, Amirpoor N, Aliakbari M. Comparing the effect of platelet rich plasma (PRP) and fetal bovine serum (FBS) on proliferation and survival of adipose-derived stem cells in fibrin scaffolds. $J$. Isfahan Medical School 32(317), 2299-2311 (2015).

81 Noroozi AA, Kheirandish M, Abolghasemi H, Gharehbaghian A. Platelet growth factors suppress ex vivo expansion and enhance differentiation of umbilical cord blood CD133+ stem cells to megakaryocyte progenitor cells. Growth Factors 28(6), 409-416 (2010).

82 Khorshidi H, Raoofi S, Bagheri R, Banihashemi H. Comparison of the mechanical properties of early leukocyteand platelet-rich fibrin versus PRGF/endoret membranes. Int. J. Dent. 2016, 1849207 (2016).

83 Hashemi TA, Alizadeh S, Heidari BM. Efficacy of a new autologus platelet gel: in vitro study. Iranian J. Pediatr. Hematol. Oncol. 2(2), 54-59 (2012).

84 Yahyavi Y, Teymouri N, Amani M et al. Application of expired platelets in the preparation of platelet gel and study of proliferative effects of expired platelet derived growth factor on variety of cell lines. Blood 7(3), 127-137 (2010). bone and biomaterials: review over the last 11 years. J. Plast. Reconstr. Aesthet. Surg. 63(10), 1615-1623 (2010).

Rezaie A, Mousavi G, Mohajeri D, Sardrodi V-A. Effect of autogenous platelet-rich plasma (PRP) on femoral cancellous bone defect healing in alloxan-induced diabetic rabbits. Aust. J. Basic Appl. Sci. 5(5), 800-808 (2011).

87 Sadatmansouri S, Ayobian N, Pourseyediyan T, Saljughidarmian S. Effect of plasma rich in growth factors on the healing of intrabony defects in human: a comparative clinical trial. J. Periodontol. Implant Dentistry 2(1), 5-11 (2011).

88 Shafiei-Sarvestani Z, Oryan A, Meimandi-Parizi A, BighamSadegh A. Histological, biomechanical and radiological evaluation of bone repair with human platelet rich plasma in rabbit model. Zahedan J. Res. Med. Sci. 23(2), 473-483 (2014).

89 Khojasteh A, Kheiri L, Motamedian SR, Nadjmi N. Regenerative medicine in the treatment of alveolar cleft defect: a systematic review of the literature. $J$. Craniomaxillofac. Surg. 43(8), 1608-1613 (2015).

90 Tavakolinejad S, Alamdari DH, Khajehahmadi S, Khordad E, Ebrahimzadeh-Bideskan A. Cleft palate reconstruction by platelet-rich-plasma and stem cell injection: histological evidences. J. Cell Animal Biol. 8(7), 114-123 (2014).
91 Tavakolinejad S, Hamidi Alamdari D, Khajehahmadi S, Ebrahimzadeh BA. Histological evidences after platelet-richplasma and adipose drived stem cells injection on critical size cleft palate. Int. J. Pediatr. 2(2.3), 88 (2014).

92 Tavakolinejad S, Khosravi M, Mashkani B et al. The effect of human platelet-rich plasma on adipose-derived stem cell proliferation and osteogenic differentiation. Iran. Biomed. J. 18(3), 151 (2014).

93 Oryan A, Alidadi S, Moshiri A, Maffulli N. Bone regenerative medicine: classic options, novel strategies, and future directions. J. Orthop. Surg. Res. 9(1), 1 (2014).

94 Tabrizi R, Karagah T, Shahidi S, Zare N. Does platelet-rich plasma enhance healing in the idiopathic bone cavity? A single-blind randomized clinical trial. Int. J. Oral Maxillofac. Surg. 44(9), 1175-1180 (2015).

95 Moradi AH, Kamalinejad A, Jalilian N, Kazemi S, Khazaei M. Using PRP and human amniotic fluid combination for osteogenesis in rabbit socket preservation. Dent. Hypotheses 6(4), 151 (2015).

96 Oryan A, Parizi AM, Shafiei-Sarvestani Z, Bigham A. Effects of combined hydroxyapatite and human platelet rich plasma on bone healing in rabbit model: radiological, macroscopical, hidtopathological and biomechanical evaluation. Cell Tissue Banking 13(4), 639-651 (2012).

97 Shafiei-Sarvestani Z, Oryan A, Bigham AS, Meimandi-Parizi A. The effect of hydroxyapatite-hPRP, and coral-hPRP on bone healing in rabbits: radiological, biomechanical, macroscopic and histopathologic evaluation. Int. J. Surg. 10(2), 96-101 (2012).

98 Parizi AM, Oryan A, Shafiei-Sarvestani Z, Bigham AS. Human platelet rich plasma plus Persian Gulf coral effects on experimental bone healing in rabbit model: radiological, histological, macroscopical and biomechanical evaluation. $J$. Mater. Sci. Mater. Med. 23(2), 473-483 (2012).

99 Paknejad M, Shayesteh YS, Yaghobee S, Shariat S, Dehghan M, Motahari P. Evaluation of the effect of plasma rich in growth factors (PRGF) on bone regeneration. J. Dent. 9(1), 59 (2012)

100 Oryan A, Alidadi S, Moshiri A. Platelet-rich plasma for bone healing and regeneration. Expert Opin. Biol. Ther. 16(2), 213-232 (2016).

101 Ghaffarpasand F, Dehghankhalili M, Shahrezaei M. Platele rich plasma for traumatic non-union fractures: a novel but controversial bone regeneration strategy. Bull. Emerg. Trauma 1(3 Jul), 99-101 (2013).

102 Wang HF, Gao YS, Yuan T, Yu XW, Zhang CQ. Chronic calcaneal osteomyelitis associated with soft-tissue defect could be successfully treated with platelet-rich plasma: a case report. Int. Wound J. 10(1), 105-109 (2013).

103 Taglialatela Scafati C, Taglialatela Scafati S, Aveta A, Cassese $\mathrm{M}$, Vitale C. Chronic frontal sinus disease: combined use of platelet-rich plasma and calvarial bone grafts for sinus obliteration in aggressive and secondary cases. Rev. Stomatol. Chir. Maxillofac. 111(4), 216-220 (2010).

104 Yuan T, Zhang C, Zeng B. Treatment of chronic femoral osteomyelitis with platelet-rich plasma (PRP): a case report. Transfus. Apher. Sci. 38(2), 167-173 (2008). 
105 Dizaji VM, Kazemi D, Rezaei M. Influence of platelet rich fibrin on biomechanical properties of primary sutured cutaneous incisional wounds. Taiwan Vet. J. 42(2), 69 (2015).

106 Ostvar O, Shadvar S, Yahaghi E et al. Effect of platelet-rich plasma on the healing of cutaneous defects exposed to acute to chronic wounds: a clinico-histopathologic study in rabbits. Diagn. Pathol. 10(1), 85 (2015).

107 Jamshidzadeh A, Hosseinabadi OK, Heidari R et al. Wound healing activity of a new formulation from platelet lysate. Trends Pharm. Sci. 2(1), 35-42 (2016).

108 Tehranian A, Esfehani-Mehr B, Pirjani R, Rezaei N, Sadat Heidary S, Sepidarkish M. Application of autologous platelet-rich plasma (PRP) on wound healing after caesarean section in high-risk patients. Iran. Red Crescent Med. J. 18(7), e34449 (2016).

109 Mehrabi Bahar M, Ali Akbarian M, Azadmand A. Investigating the effect of autologous platelet-rich plasma on pain in patients with pilonidal abscess treated with surgical removal of extensive tissue. Iran Red Crescent Med. J. 15(11), e6301 (2013).

110 Tashnizi MA, Alamdari DH, Khayami ME et al. Treatment of non-healing sternum wound after open-heart surgery with allogenic platelet-rich plasma and fibrin glue-preliminary outcomes. Indian J. Plast. Surg. 46(3), 538 (2013).

111 Alavi S, Malek F, Eshghi P, Arzhangian H. Autologous platelet-rich plasma for healing of an oncologic dehisced wound. APSP J. Case Reports 4(3), 44 (2013).

112 Karimi R, Afshar M, Salimian M, Sharif A, Hidariyan M. The effect of platelet rich plasma dressing on healing diabetic foot ulcers. Nurs. Midwifery Stud. 5(3), e3031 (2016).

113 Ravari H, Hamidi-Almadari D, Salimifar M, Bonakdaran S, Parizadeh MR, Koliakos G. Treatment of non-healing wounds with autologous bone marrow cells, platelets, fibrin glue and collagen matrix. Cytotherapy 13(6), 705-711 (2011).

114 Mehrannia M, Vaezi M, Yousefshahi F, Rouhipour N. Platelet rich plasma for treatment of nonhealing diabetic foot ulcers: a case report. Can. J. Diabetes 38(1), 5-8 (2014).

115 Keshvari SM, Hamidi Alamdari D, Ghoreifi A. A novel method for iatrogenic vesicovaginal fistula treatment: autologous platelet rich plasma injection and platelet rich fibrin glue interposition. Int. J. Pediatr. 2(2.3), 29-29 (2013).

116 Joudi M, Alamdari DH, Hyradfar M et al. Lateral traumatic esophago-cutaneous fistula in a child; platelet-rich fibrin glue challenge. Iran. Red Crescent Med. J. 15(3), 256 (2013).

117 Joudi M, Alamdari DH, Rahimi H-R. Successful treatment of congenital chyloperitoneum with platelet-rich fibrin glue. Iranian J. Pediatr. 23(3), 357 (2013).

118 Martinez-Zapata MJ, Martí-Carvajal AJ, Solà I et al. Autologous platelet-rich plasma for treating chronic wounds. Cochrane Database Syst. Rev. (5), CD006899 (2016).

- A recent and powerful systematic review about PRP application on wound disorders would be considerable for many specialties in medicine.

119 Mohammadi R, Mehrtash M, Mehrtash M, Hassani N, Hassanpour A. Effect of platelet rich plasma combined with chitosan biodegradable film on full-thickness wound healing in rat model. Bull. Emerg. Trauma 4(1), 29-37 (2016).

120 Vahabi S, Vaziri S, Torshabi M, Esfahrood ZR. Effects of plasma rich in growth factors and platelet-rich fibrin on proliferation and viability of human gingival fibroblasts. J. Dent. 12(7), 504-512 (2015).

121 Shayesteh YS, Eshghyar N, Moslemi N et al. The effect of platelet-rich plasma on healing of palatal donor site following connective tissue harvesting: a pilot study in dogs. Clin. Implant Dent. Relat. Res. 14(3), 428-433 (2010).

122 Bidar M. Evaluation of the effect of platelet-rich plasma on proliferation and differentiation of human dental pulp stem cells with or without Ga-Al-As Laser. Int. J. Pediatr. 2(2.3), 59-59 (2014).

123 Tehrani-Banihashemi A, Davatchi F, Jamshidi AR, Faezi T, Paragomi P, Barghamdi M. Prevalence of osteoarthritis in rural areas of Iran: a WHO-ILAR COPCORD study. Int. J. Rheum. Dis. 17(4), 384-388 (2014).

124 Kalbkhani M, Dehghani SN, Najafpour A, Haddadi NS, Hossein KM. Research article effects of platelet rich plasma (PRP) in treatment of experimentally induced osteoarthritis in rabbit's knee joint. Advances in Stem Cells (2014). http://ibimapublishing.com/articles/ASC/2014/994022/

125 Kalbkhani M, N Dehghani S, Najafpour A, Naji Hadadi S, Ghorbanzadeh N, Kalbkhani MH. The effect of prp in repair of femoral articular cartilage notches on experimentally induced osteoarthritis rabbit. J. Urmia Univ. Med. Sci. 26(3), 215-226 (2015).

126 Seydi N, Dehghani S. Radiological study of the effect of platelet rich plasma (PRP) on experimentally induced osteoarthritis in guinea pig's stifle joint. J. Animal Poultry Sci. 2(3), 74-78 (2013).

127 Kazemi D, Fakhrjou A. Leukocyte and platelet rich plasma (L-PRP) versus leukocyte and platelet rich fibrin (L-PRF) for articular cartilage repair of the knee: a comparative evaluation in an animal model. Iran. Red Crescent Med. J. 17(10), e19594 (2015).

128 Kazemi D, Fakhrjou A, Mirzazadeh Dizaji V, Khanzadeh Alishahi M. Effect of autologous platelet rich fibrin on the healing of experimental articular cartilage defects of the knee in an animal model. BioMed Res. Int. 2014, 486436 (2014).

129 Sadabad HN, Behzadifar M, Arasteh F, Behzadifar M, Dehghan HR. Efficacy of platelet-rich plasma versus hyaluronic acid for treatment of knee osteoarthritis: a systematic review and meta-analysis. Electronic Physician 8(3), 2115-2122 (2016).

130 Campbell KA, Erickson BJ, Saltzman BM et al. Is local viscosupplementation injection clinically superior to other therapies in the treatment of osteoarthritis of the knee: a systematic review of overlapping meta-analyses. Arthroscopy 31(10), 2036-2045 e2014 (2015).

131 Peter I, Wu K, Diaz R, Borg-Stein J. Platelet-rich plasma. Phys. Med. Rehabil. Clin. N. Am. 27(4), 825-853 (2016).

- A near to complete overview of PRP applications in various disorders.

132 Nikvarz M, Shayestehazar M, Kariminasab MH, Sajadi M, Khalilian A, Bahari M. Effects of platelet-rich plasma in 
treatment of chondromalacia patella. J. Mazandaran Univ. Med. Sci. 24(114), 44-51 (2014).

133 Moshiri A, Oryan A, Meimandi-Parizi A. Synthesis, development, characterization and effectiveness of bovine pure platelet gel-collagen-polydioxanone bioactive graft on tendon healing. J. Cell. Mol. Med. 19(6), 1308-1332 (2015).

134 Raeissadat SA, Rayegani SM, Hassanabadi H, Rahimi R, Sedighipour L, Rostami K. Is Platelet-rich plasma superior to whole blood in the management of chronic tennis elbow: one year randomized clinical trial. BMC Sports Sci. Med. Rehab. 6, 12 (2014).

135 Raeissadat SA, Fam SE, Sedighipour L, Babaei-Ghazani A. Autologous whole blood versus corticosteroid local injection in treatment of plantar fasciitis: A randomized, controlled multicenter clinical trial. Clin. Rheumatol. 36(3), 661-669 (2016).

136 Allahverdi A, Sharifi D, Abedi G, Hesaraki S, Fattahiyan H. Effect of platelet-rich plasma, low-level laser therapy ( 650 $\mathrm{nm}$ ) or their combination on the healing of Achilles tendon in rabbits: a histopathological study. Eur. J. Exp. Biol. 4(3), 201-208 (2014).

137 Allahverdi A, Sharifi D, Takhtfooladi MA, Hesaraki S, Khansari M, Dorbeh SS. Evaluation of low-level laser therapy, platelet-rich plasma, and their combination on the healing of Achilles tendon in rabbits. Lasers Med. Sci. 30(4), 1305-1313 (2015).

138 Rajabi H, Shahin HS, Norouzian M, Mehrabani D, Nazhvani SD. The healing effects of aquatic activities and allogenic injection of platelet-rich plasma (PRP) on injuries of achilles tendon in experimental rat. World J. Plast. Surg. 4(1), 66 (2015).

139 Oryan A, Moshiri A, Meimandi-Parizi A. Role of embedded pure xenogenous bovine platelet gel on experimental tendon healing, modelling and remodelling. Biodrugs 28(6), 537-556 (2014).

140 Oryan A, Moshiri A, Meimandi-Parizi A. Implantation of a novel tissue-engineered graft in a large tendon defect initiated inflammation, accelerated fibroplasia and improved remodeling of the new Achilles tendon: a comprehensive detailed study with new insights. Cell Tissue Res. 355(1), 59-80 (2014).

141 Moshiri A, Oryan A, Meimandi-Parizi A, KoohiHosseinabadi O. Effectiveness of xenogenous-based bovinederived platelet gel embedded within a three-dimensional collagen implant on the healing and regeneration of the Achilles tendon defect in rabbits. Expert Opin. Biol. Ther. 14(8), 1065-1089 (2014).

142 Seyed-Forootan K, Karimi H, Dayani A-R. PRP and Metaplasia in repaired tendon. J. Acute Dis. 3(4), 284-289 (2014).

143 Keyhan SO, Hemmat S, Badri AA, Abdeshahzadeh A, Khiabani K. Use of platelet-rich fibrin and platelet-rich plasma in combination with fat graft: which is more effective during facial lipostructure? J. Oral Maxillofac. Surg. 71(3), 610-621 (2013).
144 Abdali H, Hadilou M. Treatment of nasolabial fold with subdermal dissection and autologous fat injection added with platelet-rich plasma. J. Res. Med. Sci. 19(11), (2014).

145 Keyhan O, Hemmat S. Platelet-rich fibrin effect on increasing free fat graft survival. Int. J. Oral Maxillofac. Surg. 40(10), 1187 (2011).

146 Ahmadi-Ashtiani MA, Ehsani A, Rastegar H, M Hayati Salout H. Combination of herbal extracts and platelet rich plasma induced dermal papilla cells proliferation: Involvement of ERK and AKT pathway. Res. Pharm. Sci. 7(5), S1021 (2012).

147 Jaffary F, Nilforoushzadeh MA, Haftbaradaran E. Review on using platelet rich plasma in hair loss and hair transplantation. J. Isfahan Med. School 33(339), 970-982 (2014).

148 Faghihi G, Keyvan S, Asilian A, Nouraei S, Behfar S, Nilforoushzadeh MA. Efficacy of autologous platelet-rich plasma combined with fractional ablative carbon dioxide resurfacing laser in treatment of facial atrophic acne scars: A split-face randomized clinical trial. Indian J. Dermatol. Venereol. Leprol. 82(2), 162-168 (2016).

149 Kabiri A, Esfandiari E, Esmaeili A, Hashemibeni B, Pourazar A, Mardani M. Platelet-rich plasma application in chondrogenesis. Adv. Biomed. Res. 3 , 138 (2014).

150 Noroozi Aghideh A, Kheirandish M, Abolghasemi H, Gharehbaghian A. Comparison of cytokine growth factors in platelet supernatant, platelet lysate and activated platelet-rich plasma for therapeutic applications. Ann. Mil. Health Sci. Res. 7(3), 149-155 (2009).

151 Najafipour F, Darejeh M, Ali MM, Najafipour F. An innovative approach to platelet-rich plasma application in military medicine; a review article. J. Arch. Military Med. 3(2), e28868 (2015).

152 Moshiri A, Oryan A. Role of platelet rich plasma in soft and hard connective tissue healing: an evidence based review from basic to clinical application. Hard Tissue 2(1), 6 (2013).

153 Nekooie-Marnany N, Jaffary F, Nilforoushzadeh MA. Platelet-rich plasma (PRP) therapy in skin rejuvenation: benefits and adverse influences. J. Isfahan Med. School 33(343), 1168-1185 (2015).

154 Gholami M, Ravaghi H, Salehi M, Yekta AA, Doaee S, Jaafaripooyan E. A systematic review and meta-analysis of the application of platelet rich plasma in sports medicine. Electronic Physician 8(5), 2325-2332 (2016).

155 Beitzel K, Allen D, Apostolakos J et al. US definitions, current use, and FDA stance on use of platelet-rich plasma in sports medicine. J. Knee Surg. 28(01), 029-034 (2015).

156 Park YG, Han SB, Song SJ, Kim TJ, Ha CW. Plateletrich plasma therapy for knee joint problems: review of the literature, current practice and legal perspectives in Korea. Knee Surg. Relat. Res. 24(2), 70-78 (2012).

- Above-mentioned references were the only articles working on the state of PRP research and application specially in their country. 